Methods 2 and 3 have considerably reduced the magnitude of feto-maternal transfusion; however, the latter is advocated as evidence at present suggests that placental transfusion reduces the mortality from respiratory distress syndrome.

I thank the consultants at the Royal Gwent Hospital for allowing me to investigate patients under their care and Dr. D. G. Daniel for much helpful guidance. I am also grateful to Mrs. Collins and the labour ward staff for their incessant help.

\section{References}

Bound, J. P., Butler, N. R., and Spector, W. G. (1956). British Medical Fournal, 2, 1260.

Bound, J. P., Harvey, P. W., and Bagshaw, H. B. (1962). Lancet, 1, 1200. Combined Study from Centres in England and Baltimore (1966). British Medical fournal, 2, 907.

Duckman, S., Merk, H., Lehmann, W. X., and Regan, E. (1953). American fournal of Obstetrics and Gynecology, 66, 1214.
uckman, S., Merk, H., Lehmann, W. X., and Rega

Dunn, P. M. (1966). Fournal of Obstetrics and Gynaecology of the British Commonwealth, 73, 747.
Dunn, P. M., and Fraser, I. D. (1966). Fournal of Obstetrics and Gynaecology of the British Commonwealth, 73, 757.

Fraser, I. D., and Raper, A. B. (1962). British Medical fournal, 2, 303.

Gunther, M. (1957). Lancet, 1, 1277.

Hughes-Jones, N. C., and Mollison, P. L. (1968). British Medical fournal, 1,

Kleihauer, E., Braun, H., and Betke, K. (1957). Klinische Wochenschrift, 35, 637.

Levine, P., and Stetson, R. E. (1939). Fournal of the American Medical Association, 113, 126.

Moss, A. J., Duffie, E. D., and Fagan, L. M. (1963). Fournal of the American Medical Association, 184, 48.

Moss, A. J., Emmanouilides, G. C., Adams, F. H., and Chuang, Katok (1964). Pediatrics, 33, 937.

Redmond, A., and Isana, S. (1965). Lancet, 1, 283.

Secher, O., and Karlberg, P. (1962). Lancet, 1, 1203.

Sullivan, J. F., and Jennings, E. R. (1966). American fournal of Clinical Pathology, 46, 36 .

Terry, M. F. (1970). Fournal of Obstetrics and Gynaecology of the British Commonwealth, 77, 129.

Uscher, R., Shephard, M., and Lind, J. (1963). Acta Paediatrica, 52, 497. de Wit, D. C., and Borst-Eilers, E. (1968). British Medical fournal, 4, 139. Woodrow, J. C., and Donahoe, W. T. A. (1968). British Medical fournal, 4,

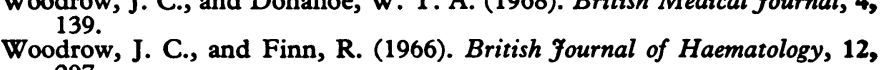
297.

Zipursky, A., Hull, A., White, F. D., and Israëls, L. G. (1959). Lancet, 1, 451.

\title{
Cell-mediated Immunity in Herpesvirus hominis Infections
}

\author{
J. M. A. WILTON, L. IVANYI, T. LEHNER
}

British Medical fournal, 1972, 1, 723-726

\section{Summary}

The cell-mediated and antibody responses to Herpesvirus hominis type 1 were investigated in patients with primary and recurrent herpetic infections. Stimulation of lymphocyte transformation with the virus and the complement fixing antibody titre did not differ significantly between patients and controls. However, macrophage migration inhibition and lymphocyte cytotoxicity were impaired in patients. The defects were specific to $H$. hominis, as Candida oblicans, which was used as an unrelated antigen, failed to show a similar abnormality. These results and preliminary sequential studies suggest that the susceptibility to recurrent herpesvirus infection may be due to an impaired production of macrophage migration inhibition factor and lymphocyte cytotoxicity in the presence of intact lymphocyte sensitization and antibody formation.

\section{Introduction}

Serological evidence of Herpesvirus hominis infection can be found in up to $90 \%$ of adults (Buddingh et al., 1953; Smith et al., 1967; Douglas and Couch, 1970), and clinical or subclinical infection is probably acquired in early childhood. Recurrent infections are common, but as these patients have serum virus neutralizing antibodies (Nagler, 1944; Douglas and Couch, 1970) the latter do not seem to have a protective function. It is possible that cell-mediated immunity might be involved in the protection from recurrent herpetic infections. Indeed, there is

\footnotetext{
Departments of Microbiolology and Oral Immunology and Microbiology, Guy's Hospital Medical and Dental Schools, London SE1 9RT

J. M. A. WILTON, B.D.S., L.D.S. R.C.S., Lecturer in Microbiology
L. IVANYI, DIP.D.S., Research Associate

T. LEHNER, M.D., M.R.C.PATH., Professor of Oral Immunology
}

evidence from cellular immunodeficiency syndromes (Cooper et al., 1968; Fulginati et al., 1968; Glasgow, 1970) and from a variety of virus infections (Blanden, 1970; Zisman et al., 1970) that cell-mediated immunity is an important defence mechanism against viruses. $H$. hominis has not been used in lymphocyte function tests except to stimulate lymphocyte transformation in an investigation of amyloidosis (Lehner et al., 1970).

The present study was undertaken to determine the part played by cell-mediated immunity in both primary and recurrent $H$. hominis infections in adults. The aim was to test the immune competence of lymphocytes to $H$. hominis type 1 by means of the lymphocyte transformation, cytotoxicity, and macrophage migration inhibition tests and to compare these with the complement fixing antibody titres.

\section{Patients and Methods}

Infections with $H$. hominis were diagnosed on clinical, cultural, cytological, and serological evidence, and at the time of the first examination the lesions had been present from one to six days. The series consisted of six patients with primary herpetic stomatitis, seven with recurrent herpes labialis at the time of examination, and six with a definite history of recurrent herpes labialis. As controls, up to 36 normal subjects with no history of recurrent herpetic infections were studied.

A sample of about $50 \mathrm{ml}$ of peripheral blood was obtained from each subject and about $40 \mathrm{ml}$ was placed in a heparinized bottle; the remainder was placed in a dry, sterile bottle, and allowed to coagulate, and the serum was removed. Leucocyterich plasma was obtained from heparinized blood, using dextran sedimentation, and leucocyte cultures were prepared for the lymphocyte transformation test (Ivanyi and Lehner, 1970).

The three tests of lymphocyte function-lymphocyte transformation, lymphocyte cytotoxicity, and macrophage migration inhibition-were performed in parallel on the same specimen of blood. Lymphocyte transformation was carried out with both autologous serum and fetal calf serum as culture supplements, but lymphocyte cytotoxicity and macrophage migration inhibition tests were performed only with fetal calf serum. 
Lymphocyte Transformation Test.-All leucocyte cultures were incubated with (1) phytohaemagglutinin (PHA, Wellcome Reagents), (2) $H$. hominis type 1 antigen, at a final dilution of $1: 200 \mathrm{v} / \mathrm{v}$ of the lyophilized stock preparation (supplied by Dr. C. M. P. Bradstreet, Public Health Laboratory Service, Colindale), and (3) C. albicans antigen at a final dilution of 1:500 v/v of the stock antigen (Bencard). The monkey kidney tissue culture in which herpesvirus was grown was also used on separate occasions to test for non-specific stimulation of lymphocytes from five subjects. DNA synthesis was assessed by ${ }^{14} \mathrm{C}$-thymidine incorporation (Ivanyi and Lehner, 1970) and all cultures were performed in triplicate. The results were expressed as the "stimulation index" which the ratio between the counts in antigen-stimulated and saline control cultures. An index greater than 2 in autologous serum and greater than 1.5 in fetal calf serum was considered to be positive.

Lymphocyte Cytotoxicity Test.-Lymphocyte cultures were established as described previously (Ivanyi et al., 1972) in the same way as for the lymphocyte transformation test but $5-\mathrm{ml}$ cultures of $1 \times 10^{6}$ cells $/ \mathrm{ml}$ were used. After three days of incubation with antigen or saline lymphocytes were added to ${ }^{51} \mathrm{Cr}$-labelled chicken erythrocytes which were used as nonspecific target cells (Perlmann et al., 1968). The results were expressed as the "cytotoxicity index" which was the ratio between the percentage of ${ }^{51} \mathrm{Cr}$ released into the supernatant by antigen-stimulated lymphocytes and that of lymphocyte-free controls. No correction was made for the unstimulated lymphocyte controls since their values have not exceeded significantly the release of ${ }^{51} \mathrm{Cr}$ from the lymphocyte-free control samples. A cytotoxicity index greater than 7 was considered to be positive for herpesvirus-stimulated cultures and 5 for candida-stimulated cultures.

Macrophage Migration Inhibition Test.-The cell-free unconcentrated culture supernatants from the lymphocyte cultures were assayed for macrophage migration inhibitory activity with oil-induced, normal guinea-pig peritoneal exudate cells (Thor et al., 1968; Rocklin et al., 1970). Saline control supernatants were reconstituted with antigen (Dumonde, 1970) and each supernatant was assayed with four capillary tubes of exudate cells. As controls, antigen in tissue culture medium and tissue culture medium alone were always used. The migration index was calculated with the formula:

Macrophage migration in antigen stimulated supernatant $\frac{1}{\text { Macrophage migration in antigen reconstituted supernatant }} \times 100$

An index of less than $80 \%$ was considered to be significant.

Complement Fixing Antibody Test.-These tests were performed by Dr. D. McSwiggan (Central Middlesex Hospital) and Mrs. V. E. Jardine (department of clinical virology, Guy's Hospital) by the method of Bradstreet and Taylor (1962).

\section{Results}

There were no differences between the patients with primary infections and those with lesions or a history of recurrent herpetic infection in any of the three tests. The results of the three groups of patients were therefore combined for comparison with the control group and these are shown in Figs. 1-3.

Lymphocyte Transformation Test.-In cultures supplemented with autologous serum and stimulated with $H$. hominis type 1 antigen 16 out of $17(94 \%)$ patients yielded a stimulation index greater than 2 compared with 22 out of $29(76 \%)$ control subjects. In cultures with fetal calf serum 8 out of $15(53.3 \%)$ patients and 13 out of $27(48 \cdot 1 \%)$ controls gave a stimulation index greater than 1.5 (Fig. 1). C. albicans stimulated cultures in autologous serum had a stimulation index greater than 2 in 10 out of $19(52.6 \%)$ patients and in 19 out of $31(58 \%)$ control subjects; cultures in fetal calf serum were positive in 4 out of 15
$(26 \cdot 6 \%)$ patients and in 12 out of $28(42 \cdot 8 \%)$ controls (Fig. 2). None of the differences between the patient and control groups whose lymphocytes were stimulated with $H$. hominis type 1 or C. albicans reached the 5\% level of significance. Furthermore, a significant difference was not found when the results of patients were compared only with controls who yielded a complement fixing antibody titre to herpesvirus greater than 1:5; indeed,

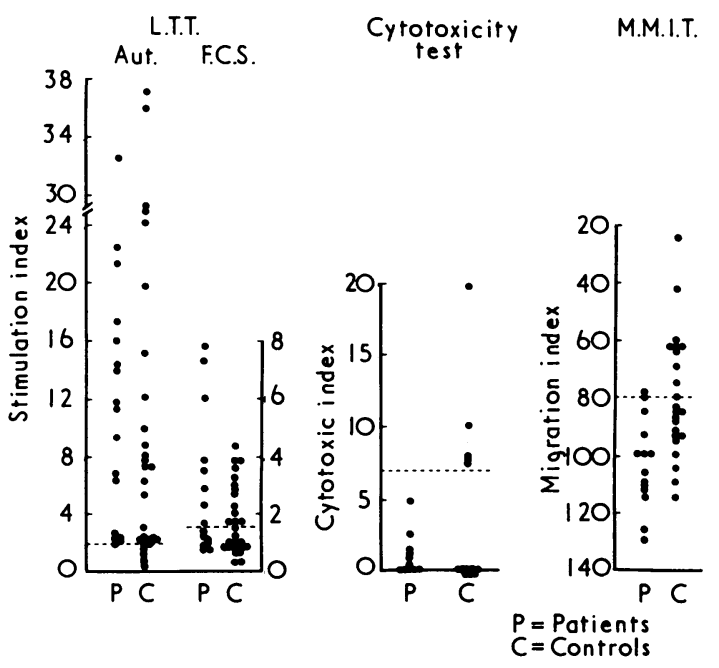
FIG. 1-Lymphocyte transformation test (L.T.T.), cytotoxicity test, and
macrophage migration inhibition test (M.M.I.T.) with $H$. hominis type 1 macrophage migration inhibition test (M.M.I.T.) with $H$. hominis type 1
antigen in patients and controls. AUT. = Autologous serum. F.C.S. $=$ fetal antigen in pati
calf serum.

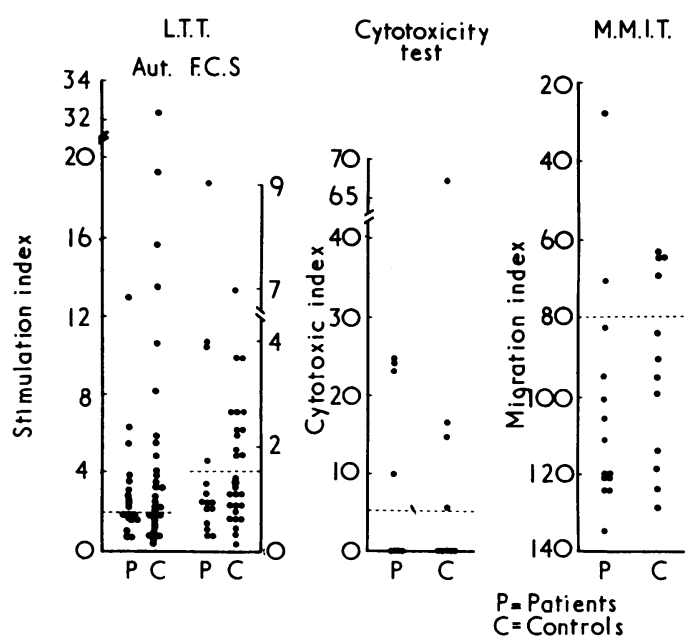

FIG. 2-Lymphocyte transformation test (L.T.T.), cytotoxicity test, and macrophage migration inhibition test (M.M.I.T.) with C. albicans antigen in patients and controls. AUT. = Autologous serum. F.C.S. = Fetal calf serum.

$94 \%$ of these controls showed a stimulation index greater than 2 . The kidney tissue culture failed to stimulate lymphocytes from five subjects, so that a non-specific stimulation was excluded. When lymphocyte cultures were stimulated with phytohaemagglutinin, all patients and control subjects gave a stimulation index greater than 50 (Fig. 3).

Lymphocyte Cytotoxicity Test.-A cytotoxicity index greater than 7 was not yielded by lymphocytes from any of the patients but those from 5 out of $13(38.4 \%)$ control subjects exceeded this value in cultures stimulated with $H$. hominis type $1\left(\chi^{2}=\right.$ 5.32; $\mathrm{P}<0.05)$. When cultures were stimulated with $C$. albicans 4 out of $8(50 \%)$ patients and 4 out of $9(44.4 \%)$ control subjects yielded a cytotoxicity index greater than 5 . The results were similar when cytotoxicity from patients was compared with those from controls who yielded a complement fixing antibody titre greater than 1:5. 
Macrophage Migration Inhibition Test.-In supernatants from cultures stimulated with $H$. hominis type 1 only 1 out of 14 patients $(7 \cdot 1 \%)$ gave a migration index of less than $80 \%$ compared with 9 out of $23(39 \cdot 1 \%)$ control subjects $\left(\chi^{2}=5 \cdot 47\right.$; $P<0.02)$. The significance rose to the $1 \%$ level when only controls with antibody titres greater than 1:5 were compared with patients. When culture supernatants from lymphocyte cultures stimulated with $C$. albicans were assayed 2 out of 14 $(14.1 \%)$ patients and 4 out of $12(33.3 \%)$ controls were positive $\left(\chi^{2}=1 \cdot 25 ; P>0.3\right)$.

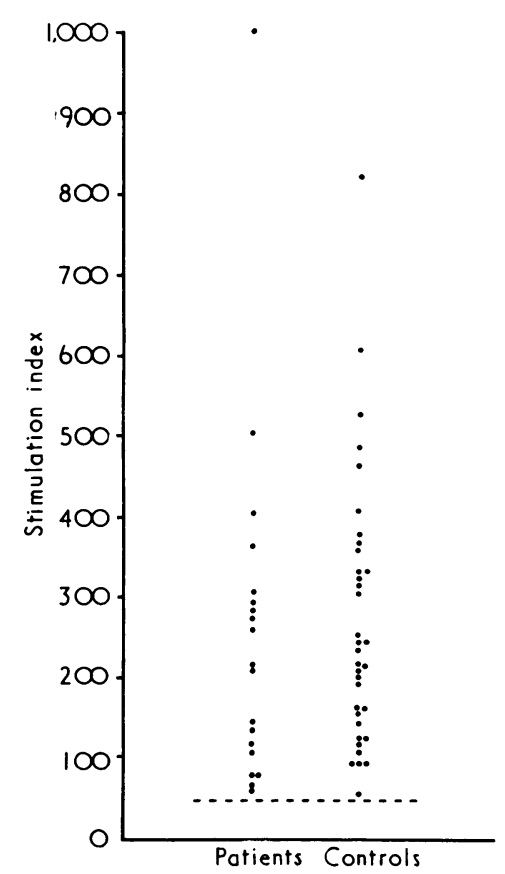

FIG. 3-Phytohaemagglutinin-induced lymphocyte transformation in patients and controls.
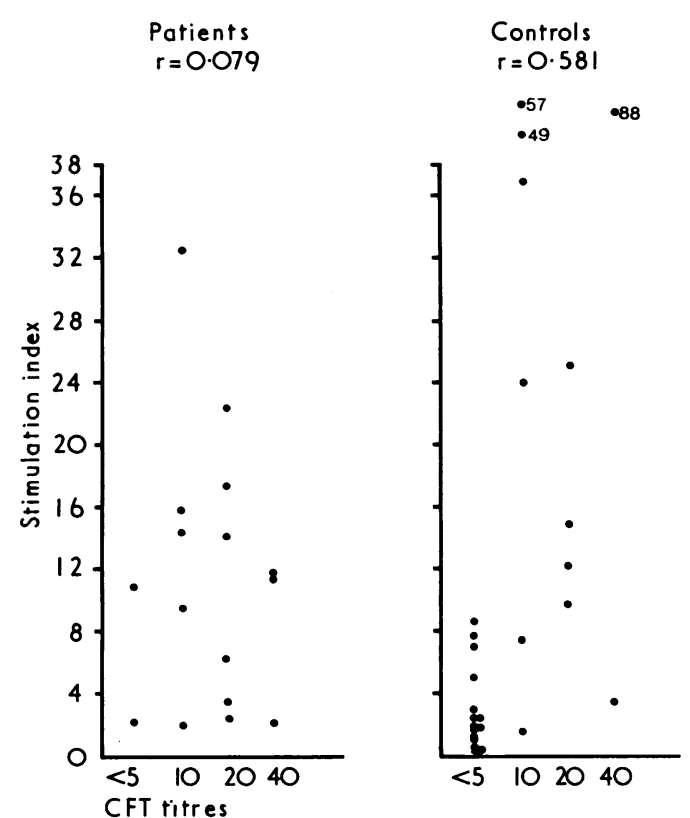

FIG. 4-Lymphocyte transformation and complement fixing antibodies in patients and controls $\left(\log _{2}\right.$ titres; $0=<1: 5$.)

Complement Fixing Antibody Test.-Only two patients had antibody titres less than $1: 5$ and the others showed titres ranging from $1: 5$ to $1: 40$. In the control group 15 subjects gave titres of less than $1: 5$ and 12 yielded titres from $1: 10$ to $1: 40$. The mean titre in the patients was $2.38 \log _{2}$ units $( \pm 0.305)$ and in controls $1 \cdot 11 \log _{2}$ units $( \pm 0 \cdot 272)$, and this difference was significant by Student's $t$ test ( $P<0.01$, D.F. 42). A comparison between the antibody titre and stimulation index (Fig. 4) showed a significant correlation between these indices in the control group $(\mathbf{r}=0.581 ; \mathrm{P}<0.01)$ but not in the patients $(r=$ 0.079).

\section{Discussion}

The results of this study suggest that patients with primary or recurrent herpetic infections possess lymphocytes specifically sensitized to $H$. hominis type 1 , and that these are capable of in-vitro transformation with the specific antigen. This finding is consistent with the results of skin testing (Nagler, 1944; Rose and Molloy, 1947), which showed that delayed hypersensitivity responses were elicited only in patients with serological evidence of previous infection. Skin testing was not performed in our patients, since there is no safe skin-testing preparation available at present, so that no correlation could be made between in-vitro and in-vivo results.

The differences between the stimulation index in autologous serum and fetal calf serum might be taken to indicate that antibody or antigen/antibody complexes were responsible for enhanced lymphocyte transformation (Ivanyi and Lehner, 1971). The stimulation index in autologous serum was consistently greater than that found in fetal calf serum and it has been shown that antigen/antibody complexes produce greater lymphocyte transformation than antigen alone (Oppenheim, 1969). No correlation was found between the stimulation index and antibody titre in patients with herpetic infections but there was a significant relation between these two indices in the control group $(P<0.01)$. It would seem that patients with herpetic infections show a dissociation between lymphocyte transformation and antibody production in contrast to normal subjects. All the patients with recurrent infections had antibodies in their serum and the dissociation between stimulation index and antibody titre supports the hypothesis that recurrent infection is due to a cell-mediated immunodeficiency involving macrophage migration inhibition and lymphocyte cytotoxicity. A similar dissociation has been found in patients with chronic mucocutaneous candidiasis between fluorescent antibody titre and stimulation index in autologous serum to $C$. albicans (Lehner et al., 1972).

Since the ability to stimulate lymphocytes did not differ between patients and controls, protection from recurrent infection cannot be solely a function of lymphocyte sensitization. It has been suggested (Dumonde, 1970) that the expression of cell-mediated immunity may depend on the production of lymphokines such as macrophage migration inhibition factor. A deficiency of this factor was also postulated as the cause of cutaneous anergy in chronic candidiasis (Chilgren et al., 1969), and such a deficiency has been found in one patient (Valdimarsson et al., 1970). We have found in another study (Lehner et al., 1972) that lymphocytes from patients with chronic mucocutaneous candidiasis show an impaired macrophage migration inhibition and cytotoxicity response to $C$. albicans.

In this study the macrophage migration inhibition test showed a significant difference between patients and controls. This raises the possibility that susceptibility to recurrent herpetic infection is due to an impaired production of macrophage migration inhibition factor by these patients. This is supported by preliminary sequential studies in two patients with primary herpetic infection and two patients with recurrent lesions who initially failed to yield a positive macrophage migration inhibition reaction but later converted to a positive response. All four patients have been free of recurrent infection for 20 months. Furthermore, a positive cytotoxity response was not found in patients when their lymphocytes were stimulated with herpesvirus and such a defect might also contribute to recurrent infection.

A significant difference was not observed between patients and controls when $C$. albicans was used as a stimulant in the 
three lymphocyte function tests. It would seem that the cellular immune response to an unrelated organism is not impaired in patients with herpetic infection and that the defects in macrophage migration inhibition activity and lymphocyte cytotoxicity are confined to $H$. hominis type 1 antigen. Long-term sequential studies will be pursued to test the hypothesis that impaired macrophage migration inhibition and lymphocyte cytotoxicity responses in the presence of a positive lymphocyte transformation and antibody reactions are responsible for recurrent herpetic infection.

We thank Dr. C. M. P. Bradstreet and Dr. J. M. B. Edwards for the supply of herpesvirus, Dr. D. McSwiggan and Mrs. V. E. Jardine for performing the complement fixation tests, and Miss J. Ramsay and Mr. R. G. Ward for expert technical help.

\section{References}

Blanden, R. V. (1970). Fournal of Experimental Medicine, 132, 1035. Bradstreet, C. M. P., and Taylor, C. E. D. (1962). Monthly Bulletin of the Ministry of Health and the Public Health Laboratory Service, 21, 96.
. Pediatrics, 11, 595.
Chilgren, R. A., Quie, P. G., Meuwissen, H. J., Good, R. A., and Hong, R. (1969). Lancet, 1, 1286.

Cooper, M. D., Chase, H. P., Lowman, J. T., Krivit, W., and Good, R. A. (1968). American fournal of Medicine, 44, 499.

Douglas, R. G., and Couch, R. B. (1970). Fournal of Immunology, 104, 289.

Dumonde, D. C. (1970). Proceedings of the Royal Society of Medicine, 63, 899.

Fulginati, V. A., et al. (1968). In Birth Defects Original Articles Series, ed. D. Bergasma, vol. 4, p. 129. New York, National Foundation March of Dimes.

Glasgow, L. A. (1970). Archives of Internal Medicine, 126, 125

Ivanyi, L., and Lehner, T. (1970). Archives of Oral Biology, 15, 1089.

Ivanyi, L., and Lehner, T. (1971). International Archives of Allergy and Applied Immunology, 41, 620

Ivanyi, L., Wilton, J. M. A., and Lehner, T. (1972). Immunology, 22, 142.

Lehner, T., Cameron, S. J., and Ward, R. G. (1970). Clinical and Experimental Immunology, 6, 439.

Lehner, T., Wilton, J. M. A., and Ivanyi, L. (1972). Immunology. In press.

Nagler, F. P. O. (1944). Fournal of Immunology, 48, 213.

Oppenheim, J. J. (1969). Annals of Allergy, 27, 305.

Perlmann, P., Perlmann, H., and Holm, G. (1968). Science, 160, 306.

Rocklin, R. E., Meyers, O. L., and David, J. R. (1970). Fournal of Immuno$\log y, 104,95$.

Rose, H. M., and Molloy, E. (1947). Fournal of Immunology, 56, 287.

Smith, I. W., Peutherer, J. F., and MacCallum, F. O. (1967). Fournal of Hygiene, 65, 395

Thor, D. E., Jureziz, R. E., Veach, S. R., Miller, E., and Dray, S. (1968). Nature, 219, 755 .

Valdimarsson, H., Holt, L., Riches, R. C., and Hobbs, J. R. (1970). Lancet,

1, 1259. 104,1155 .

\section{PRELIMINARY COMMUNICATIONS}

\section{Trimethoprim Resistance determined by $\mathbf{R}$ Factors}

\author{
M. P. FLEMING, NAOMI DATTA, \\ R. N. GRÜNEBERG
}

British Medical fournal, 1972, 1, 726-728

\section{Summary}

$\mathbf{R}$ factors conferring a high level of resistance to trimethoprim have been identified in one strain of Escherichia coli and one of Klebsiella aerogenes, both isolated from infected urines.

\section{Introduction}

Trimethoprim (TMP) became available for general use in medicine three years ago. It is a synthetic substance which inhibits the enzyme dihydrofolate reductase, necessary for the essential synthesis by bacteria of folinates, and it acts synergistically with sulphonamides, whose antibacterial effect is on an earlier stage in the same synthetic pathway (Hitchings, 1969). Therapeutic preparations of trimethoprim are always put up in combination with a sulphonamide $(\mathrm{Su})$. The rationale for this is to make use of their synergistic antibacterial effects and at the same time prevent the emergence of mutant bacteria resistant to either drug (Bushby, 1969). The combination of trimethoprim and sulphonamide has proved useful in many kinds of bacterial

Bacteriology Laboratory, Wellcome Veterinary Research Station, Tunbridge Wells, Kent

M. P. FLEMING, O.N.C. (Applied Biology), Technician

Royal Postgraduate Medical School, London W.12

NAOMI DATTA, M.D., M.R.C.PATH., Senior Lecturer in Bacteriology

University College Hospital, London WC1E 6AU

R. N. GRÜNEBERG, M.B., B.S., M.R.C.PATH, Consultant Bacteriologist infection, and notably in combating invasion of the urinary tract by Enterobacteriaceae (Grüneberg and Kolbe, 1969; Reeves et al., 1969). Sulphonamide resistance is not uncommon in bacteria causing urinary infection (Williams and Leigh, 1966; Grüneberg, 1971; Shaw et al., 1972). The incidence of resistance to trimethoprim is low; it is currently found, in our experience, in about $1 \%$ of urinary infections with Escherichia coli (Grüneberg, 1971).

We report here the isolation from infected urines of bacteria highly resistant to both trimethoprim and sulphonamide in which the resistances were determined by transmissible $R$ factors.

\section{Materials and Methods}

Bacteria.-Strains of Enterobacteriaceae, highly resistant to trimethoprim, were collected by Dr. E. Joan Stokes, Miss Pamela Waterworth, and R.N.G. from clinical material sent to the diagnostic laboratories at University College Hospital. Antibiotic sensitivity tests were made in the first instance by a disc diffusion method in which the size of zone given with the test strain is compared with that given using a standard sensitive strain (Stokes, 1968). Sulphonamide and trimethoprim sensitivity tests were performed separately on a medium free of inhibitors. There were five cultures of $E$. coli whose minimal inhibitory concentration (M.I.C.) for trimethoprim was $16 \mu \mathrm{g} / \mathrm{ml}$ or more, all resistant also to sulphonamide and one of them to tetracycline. There were three cultures of Klebsiella spp. and one of Enterobacter aerogenes, all resistant to ampicillin, trimethoprim (M.I.C. $32 \mu \mathrm{g} / \mathrm{ml}$ or more), and sulphonamide, and with various patterns of resistance to streptomycin (S), tetracycline (T), chloramphenicol (C), nalidixic acid, and nitrofurantoin. One further trimethoprim-sulphonamide-resistant $E$. coli was isolated subsequently (see below).

Minimal Inhibitory Concentrations.-Small inocula (broth cultures diluted sufficiently to give isolated colonies) were streaked on plates lacking trimethoprim-sulphonamide inhibitor (Waterworth, 1969) and containing serial dilutions of drug. The M.I.C. was taken as the lowest concentration which prevented visible growth. 